\title{
Three Cases of Rare Localization of the Hydatid Cyst
}

Mounira Khezami, Hiba Bellaaj ${ }^{\star}$, Achraf Abdennadher, Khalil Amri, Mounir Hamdi and Lotfi Nouisri

*Department of Plastic Surgery, Hospital Habib Bourguiba Sfax, El Ferdaws 3089, Sfax, Tunisia

*Corresponding author: Hiba Bellaaj, Hospital Habib Bourguiba Sfax, Plastic Surgery, El Ferdaws 3089, Sfax, 3089 Tunisia, Tel: +21625801661; E-mail: hiba.bellaaj.cpre@gmail.com

Received date: October 14, 2017; Accepted date: January 02, 2018; Published date: January 08, 2018

Copyright: $\bigcirc 2018$ Khezami M, et al. This is an open-access article distributed under the terms of the creative commons attribution license, which permits unrestricted use, distribution, and reproduction in any medium, provided the original author and source are credited.

\section{Abstract}

Hydatid disease is prevalent throughout much of the world. However, bone and muscle echinococcosis are rare and often misdiagnosed. We report three cases: the first case, 38-year-old man had a primary sacral hydatid cyst, the second one, 37-year-old man, and the third one both had a primary muscle hydatidosis of the adductors of left thigh. The treatment was surgical for all three patients. Healing was obtained for the 2 muscular sites whereas the recurrence was the characteristic of the osseous localization despite several surgical resections.

Keywords: Hydatid disease; Echinococcosis; Bone; Muscle; Surgery

\section{Introduction}

Hydatid disease, or echinococcosis, is classified as a helminthic infection caused by the tapeworm Echinococcus granulosus. Bone and muscle hydatidosis are rare. Hydatid cyst of bone constitutes only $0.5-2 \%$ of all hydatidosis and muscle hydatidosis constitutes only $3-5 \%$ of all cases [1-3].

\section{Methods}

This study 3 cases who presented a rare localization of the hydatid cyst followed and treated in the department of orthopedics and traumatology of the military hospital of Tunis between 2002 and 2017.

\section{Presentation of the Cases}

\section{Case 1}

A chief sergeant, aged 38 years, operated five years ago for sacral hydatid cyst, presented with back pain, lumbar sciatica L5 S1 and urinary disorders. Throw the interrogation we found the notion of dogs in the entourage. The pelvic radiography shows an osteolytic lesion of the sacral bone. We complete by CT scan which showed intrapelvic cystic picture invading the sacrum, the right sacroiliac joint and invading the soft tissue. A hydatid serology was negative. Surgical treatment consisted on a wide drainage of hydatid cavity dug in the sacral bone by a posterior surgical approach, with removal of the entire cyst by gentle aspiration associated to an abundant rinsing of soft tissue and cysts with hypertonic saline, after verifying that there was no opening of the dura. After surgery, the evolution was good with recovery of perineal sensation and anal tone. The patient was put on long-term Albendazole treatment, with a regular physical reeducation program. One year later, the patient had had similar symptoms, for which she had undergone the same procedure. Five years later, he again had surgical drainage and postoperatively was treated with Mebendazole. Actually, after 5 years of follow-up, our patient is well.

\section{Case 2}

A 37-year-old corporal with no significant pathological history, born in a rural environment but without the notion of animal contagion, consulted us for a tumefaction of the anterior and internal surface of the root of the left thigh increased in size since 5 year. The patient reports a history of weight loss not encrypted by the patient.

The standard radiograph of the femur did not reveal any bone lesions.

Ultrasound was in favor of liposarcoma and MRI showed an eleven centimeter long axis formation with a liquid content in which numerous nodular protein signal formations.

Note that abdominal ultrasound was normal and that the hydatic serology was positive.

A direct surgical approach was performed with an aspect in favor of a hydatid cyst. A monobloc resection was then performed. Medical treatment with Mebendazole was prescribed.

\section{Case 3}

A 25-year-old chief sergeant, with no significant pathological history, born in a rural environment but without the notion of counting animals consulted us for a soft swelling, insensitive and moving of the posteromedial side of the root of the left thigh lasting for 2 years and having gradually increased in size up to $15 \mathrm{~cm}$ in diameter (Figure 1). The patient reports the notion of alteration of the general state, associated with a fever, neglected by him.

A hydatid serology was made to him that was negative for the ELISA test and positive for the Western Blot. Moreover, with ultrasound, is described an aspect evoking a cystic lymphangioma at the expense of the adductor thick walls with vascularized and having a plurality of stalls spans.

The patient was sent for an MRI for the exact localization and extent of the mass and to rule out any involvement of the bone. It revealed multiple small cystic lesions, giving the classical "honeycomb" appearance framing with cystic lymphangioma. Dynamic MRI angiography showed a significant enhancement of the wall and its partitions by an arterial branch of the deep femoral artery. 
Citation: Khezami M, Bellaaj H, Abdennadher A, Amri K, Hamdi M, et al. (2018) Three Cases of Rare Localization of the Hydatid Cyst. J

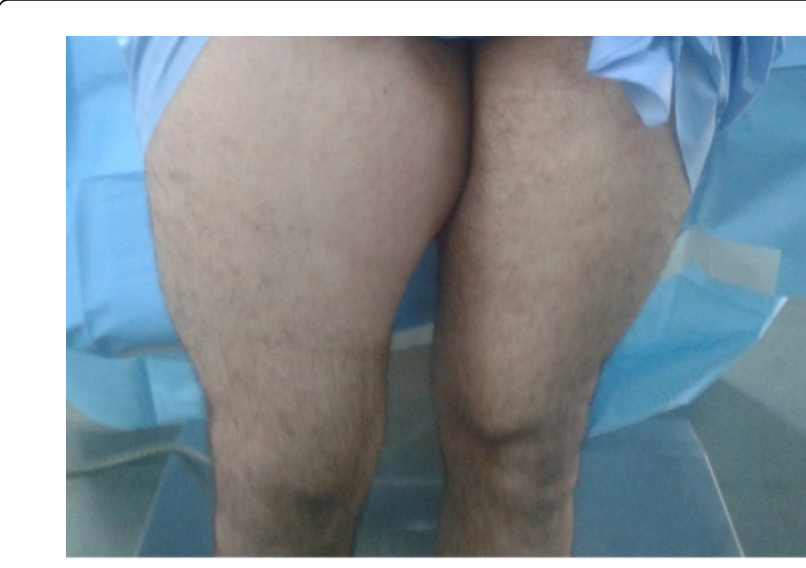

Figure 1: Clinical aspect of a hydatid cyst of the right thigh root.

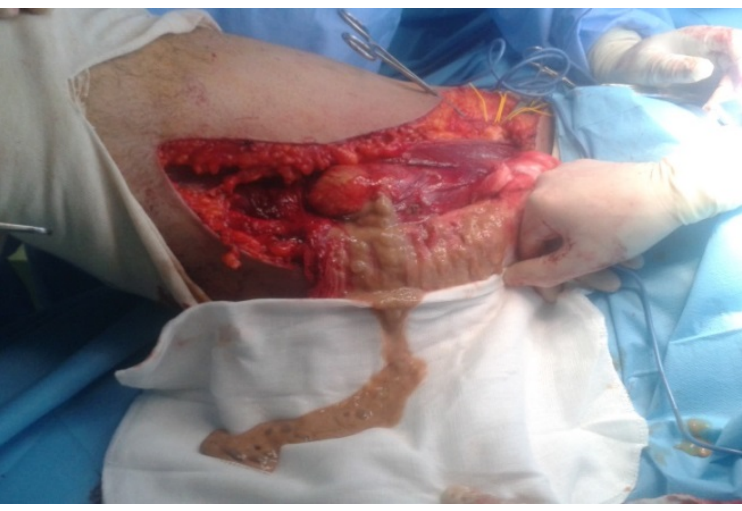

Figure 2: Photo peroperative: revamped aspect in favor of a muscular hydatid cyst of the right thigh root.

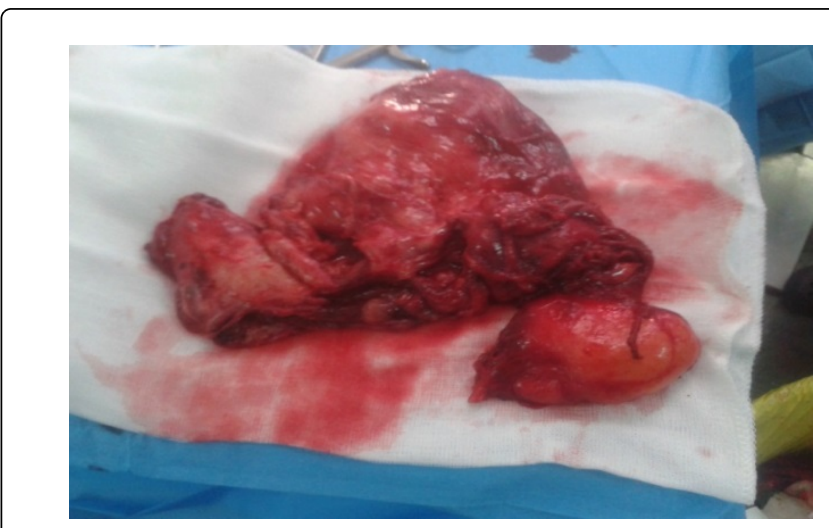

Figure 3: Piece of resection of a muscular hydatid cyst of the right thigh root.

A direct surgical approach was performed with an aspect in favor of a hydatid cyst (Figure 2). A monobloc resection was then performed (Figures 3-5). Medical treatment with Mebendazole was prescribed.

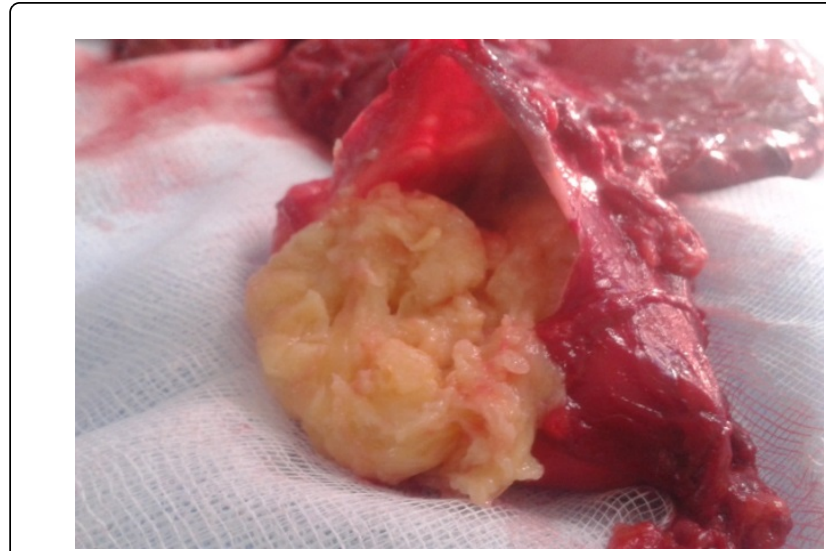

Figure 4: Intracystic product appearance of a muscular hydatid cyst of the right thigh root.

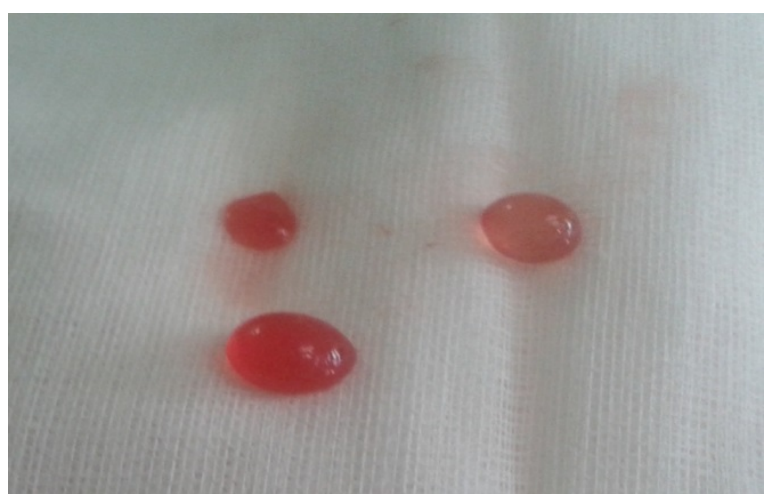

Figure 5: Hydrated vesicles.

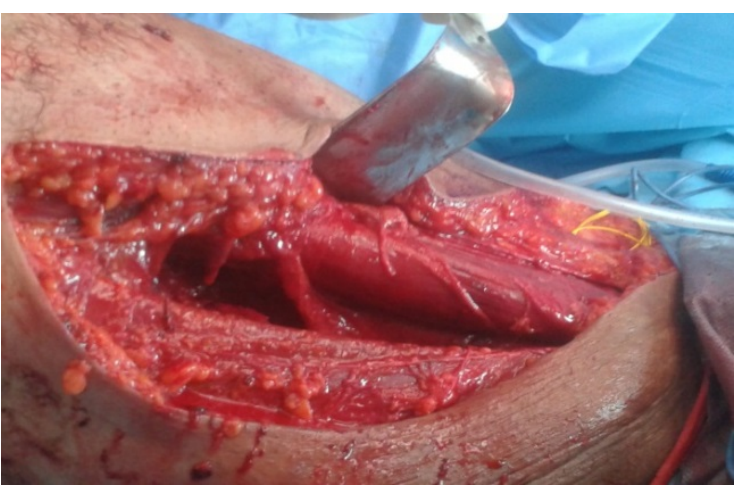

Figure 6: Photo peroperative: complete excision of a hydatic cyst of the adductors of the right thigh.

\section{Discussion}

Echinococcosis is a cosmopolitan disease affecting both humans and many mammals, without any predilection for sex or age [4]. 
Most cysts (60\%) develop in the liver; other development sites are the lung (20\%) and less frequently the bones and muscles.

The muscular localization of the hydatid cyst occupies the $3^{\text {rd }}$ place after the liver and the lung [5], its rarity can be explained by the efficacy of the hepatic and pulmonary barriers that oppose the migration of the hexacanth embryo into the systemic circulation [5], the muscular environment which is not conducive to the growth of hydrous larvae due to the production of lactic acid toxic to the parasite and the muscular contraction which prevents its fixation [5]. Muscular echinococcosis usually occurs in the proximal muscles of the limbs $[5,6]$. This attack is most often isolated and primitive.

Among the bone sites, spinal localization is the most frequent (44\%) $[7,8]$. That of the basin comes in second place with a frequency of $16 \%$ $[7,8]$.

The clinical signs for these two sites are not specific. The beginning is generally insidious by the appearance of a very limited and painless swelling of varying size and soft consistency with a general condition preserved. For muscular localization, the hydatid cyst may simulate a lipoma, a calcified hematoma, a benign or malignant tumor, or an abscess in case of cracking or surinfection (Figure 1) [5,9].

For bone sites, the reason for consultation is pelvic or joint pain with limping if the coxo-femoral joint is affected [1], sometimes it may be swelling of soft parts with fistulization or neuralgia [7]. Hydatic serology provides diagnostic certainty when it is positive, but it is often negative.

The radiological aspect is not pathognomonic [7]. It allows muscular localizations to eliminate bone damage and to show calcifications in the case of an aged cyst [4]. For bone localizations, the radiography typically exhibits wide, poorly limited, areolar lytic images, giving the classical "honeycomb" appearance without condensation or periostatic apposition $[7,8]$.

Ultrasound is the examination of choice for the diagnosis of muscular localizations; its reliability is estimated at $95 \%[5,6]$. It specifies the fluidic nature of the swelling and its seat. However, there are atypical forms where the lesion is either mixed or solid pseudotumor with or without rounded transonore images within it, the same for deep locations where the reliability of ultrasound decreases.

$\mathrm{CT}$ is the exam of choice for bone lesions to better define bone lesions and their possible extension in soft tissues [7,8]. MRI allows an axial, frontal, sagittal and oblique multiplanar study and makes it possible to specify the relations with the vascular pedicles.

Treatment of the muscular or bone hydatid cyst is surgical. The technique of choice remains monoblock excision with total perikystectomy, but this is not always possible when the cyst is remodeled, deep or in contact with the vessels [5].
In its bone localization, the hydatid cyst does not have a pericystic membrane $[7,8]$ and the progression of the lesions is effected by multidiverticular budding from small mother vesicles in all directions $[7,8]$. Thus, the bone environment seems to give it a "relative malignancy" $[7,8]$, which makes this surgical treatment difficult especially in the very extensive and deep pelvis $[7,8]$. This surgery never guarantees healing. Surgical resection must be careful to avoid the opening of the cyst due to the risk of anaphylactic shock (Figure 6).

Medical treatment has little place in the treatment of muscle cysts. It is prescribed as an adjuvant to surgery in relapses, inoperable cysts or in numerous hydatid cysts for fear of having left small cysts unseen in surgery, provided to be used for a prolonged period (more than 03 months).

Recurrences are frequent, especially for bone sites, so the best treatment remains preventive.

\section{Conclusion}

The diagnosis of bone hydatid cyst as well as muscle is not obvious a series of complementary examinations is necessary to guide the diagnosis. Confirmation is by histological examination.

\section{References}

1. Amar MF, Chbani B, Lahrach K, Marzouki A, Boutayeb F (2010) Primary hydatid cyst of the thigh revealed by cruralgia. A case report. J Traumatol Sport 27: 146-148.

2. Soufi M, Lahlou MK, Messrouri R, Benamr S, Essadel A, et al. (2010) Kyste hydatique du psoas: a propos de deux cas: Hydatid cyst of the psoas: a report of two cases. J Radiol 91: 1292-1294.

3. Melis M, Marongiu L, Scintu F, Pisano M, Capra F, et al. (2002) Primary hydatid cysts of psoas muscle. ANZ J Surg 72: 443445.

4. Alouini Mekki R, Mhiri Souei M, Allani M, Bahri M, Arifa N, et al. (2005) Hydatid cyst of soft tissues: MR imaging findings (Report of three cases). J Radiol 86: 421-425.

5. Girard J, Becquet E, Limousin M, Chantelot C, Fontaine C (2005) Ostéome ostéoïde de l'os trapézoïde : à propos d’un cas et revue de la littérature. Chir Main 24: 35-38.

6. Mseddi M, Mtaoumi M, Dahmene J, Ben Hamida R, Siala A, et al. (2005) Hydatid cysts in muscles: eleven cases. Rev Chir Orthopédique Réparatrice Appar Mot 91: 267-271.

7. Kabi F, Ben yahia E, Faiz S, Bennis R, Mkinsi O (2005) Echinococcose de l'os iliaque (A propos d'un cas). Rev Maroc Chir OrthopTraumato 23: 53-55.

8. Arteaga Ch, Gueguen GE, Richez P, Belliol E, Baréa D, et al. (1998) Mise $\mathrm{Au}$ Point Atteintes Ostéo-Articulaires D'origine Parasitaire : Les Tréponématoses Osseuses. J Radiol 79: 1363.

9. Jerbi Omezzine S, Abid F, Mnif H, Hafsa C, Thabet I, et al. (2010) Kyste hydatique primitif de la cuisse. Une localisation rare. Rev Chir Orthopédique Traumatol 96: 105-108. 